\title{
Economic Integration and Quality Standards in a Duopoly Model with Horizontal and Vertical Product Differentiation
}

\author{
Jørgen Drud Hansen and Jørgen Ulff-Møller Nielsen \\ Aarhus School of Business
}

\begin{abstract}
This paper examines the effect of trade barriers on quality levels in a duopoly model for two countries where products are both vertically and horizontally differentiated. In the absence of quality regulation the producer in the large country produces a higher quality than the producer in the small country. Moreover, the quality levels between the two producers converge in case of market integration i.e. when the trade barrier is reduced. If a common minimum quality standard is introduced, which forces the low quality producer to increase the quality of his product, the high quality producer reacts strategically by lowering the quality of his product. On unregulated markets, market integration increases welfare in both countries if they are almost of similar size. However, if the countries are very asymmetrical with respect to size, market integration may harm welfare in the large country. Introducing a minimum quality standard also has ambiguous effects on welfare.
\end{abstract}

- JEL classification: F12, F13, F14

- Keywords: Vertical product differentiation, Horizontal product differentiation, Market integration, Duopoly, Minimum quality standard

\footnotetext{
*Corresponding address: Associate professor Jørgen Ulff-Møller Nielsen, Department of Economics, Aarhus School of Business, Denmark. E-mail: JUM@ASB.DK

The paper was presented at European Trade Study Group Seventh Annual Conference 2005, Dublin. (C2006-Center for International Economics, Sejong Institution, All Rights Reserved.
} 


\section{Introduction}

On markets for vertically differentiated products, product quality is a strategic variable for firms. In the pioneering work of Gabszewicz and Thisse (1979), product quality has been analyzed formally in a duopoly model based on vertical product differentiation. This analysis has been followed by a large number of analyses of determination of product quality in duopoly models. Basically, market equilibrium in these models is determined in a two-stage game between the two companies. Product qualities are determined in the first-stage game leaving prices or output to be determined in the second-stage game.

Several analyses in this tradition focus on the impacts of implementation of a minimum quality standard, which changes the quality of the products not only for the producer, who is obliged to raise his product quality level, but also for the producer, who produces above the required quality level. In a seminal paper on this issue Ronnen (1991) shows that a minimum quality standard, which effectively forces the low quality producer in a duopoly to raise his product quality, induces the high quality producer to raise his product quality too. The model of Ronnen is based on pure vertical product differentiation, Bertrand competition on prices and quality dependent fixed costs. This result was corroborated by Crampes and Hollander (1995) in a duopoly model where the variable production costs depend on the level of quality. The positive impact of a minimum quality standard on the quality level for the high quality producer also appears in case of Cournot instead of Bertrand competition; see Valetti (2000) for this result. The models referred to above all illustrate that a minimum quality standard induces the high quality producer for strategic reasons to raise quality of his product. In other respects the models diverge strongly in conclusions on e.g. welfare of countries and profit of the two producers.

Duopoly models with vertical product differentiation have also been analysed in a two country case. Boom (1995) examines the effects of implementation of asymmetric minimum quality standards for two countries i.e. the minimum quality standard differs across countries. If one of the countries chooses to keep its minimum standard above the standard of the other country, the low quality producer raises the quality of his product to be able to sell on both markets. Whether or not minimum quality standards are uniform across countries, international spill-overs are unavoidable. However, the two-country analysis of Boom only deals rudimentarily with the trade aspect. Trade costs are neglected and hence, the location of the two producers is without importance for prices, quantities 
and qualities. Country welfare depends of course on the location of the producers as the companies have non-negative profits. Recently, a similar two country model has been developed by Lutz (2000). Also in his model, markets are completely segmented, so there is no arbitrage between countries.

However, these results are based on the assumption of pure vertical product differentiation. When a minimum quality standard forces the low quality producer to raise the quality of the product he produces, the immediate effect is increased competition on the market. To mitigate this effect, the high quality producer reacts by raising the quality level of his product. In other words the quality reaction functions are positively sloped that is, qualities are strategic complements.

The question is whether the assumption of pure vertical product differentiation is relevant. According to Shaked and Sutton (1987:132) this is not the case. They claim that "[..] a striking feature of the existing literature is the fact that the results obtaining in cases of the "pure vertical" and "pure horizontal" differentiation literatures are sharply different, but the - empirical relevant - case in which both types of attribute are present, has not been widely studied". Garella $(2003,2006)$ has recently developed such a generalized model where consumers' tastes differentiate both vertically and horizontally. If one of the producers in this set-up raises the quality level of his product, he gains a larger market share although the gain is limited by the consumers' horizontal preferences. The other producer will react defensively and save quality development costs by lowering the quality of his product and only produce for his most loyal customers. Quality levels are thus strategic substitutes i.e. when one company raises its quality level, the other company will react by lowering its quality. As shown by Garella this reverses the conclusions on the impacts of regulating the market by implementation of a minimum quality level compared with the case of only vertically differentiated tastes. If a minimum quality standard is introduced, the low quality producer may be forced to raise the quality of his product and the high quality producer then reacts by lowering the quality of his product.

The purpose of this paper is to extend the above analyses to a two country model. The markets might or might not be regulated by a common minimum quality standard. To examine this question, a model is developed which bears close affinity to the model of Garella $(2003,2006)$. The model includes horizontal as well as vertical product differentiation and is basically based on the same specifications of utility and technology (costs) as the model of Garella. However, the analysis introduces two countries with one producer located in each country. The markets in the two 
countries are partially integrated as trade costs prevail i.e. the producer in each country has a competitive advantage on the domestic market.

Two main findings follow from this extension of Garellas model. First, the relative size of the markets plays a role for the ranking of qualities between the two producers. If the producers are equally cost effective in production and developing quality, the high quality producer will appear in the country, where the domestic market is largest. In previous analyses, the ranking of producers with respect to quality is either described as a first mover advantage (see e.g. Ronnen, 1991) or as a result of cost efficiency asymmetries (see e.g. Garella, 2003, 2006). Quality development is assumed to involve fixed costs and in the model developed in the following, a large domestic market offers more favourable conditions for development of quality as fixed costs might be spread over more units on the large market. Market integration i.e. a decrease of trade costs weakens the importance of a big domestic market and hence, quality increases for the producer on the small market, but decreases for the producer on the big market. In general, the welfare effects of market integration are ambiguous.

Secondly, implementation of a common minimum quality standard which forces the producer in the small country to raise his quality level may induce the producer located in the large country to reduce his quality level. This basic result is identical with the model of Garella, but an additional point appears, if trade costs are reduced. In that case the small country's producer maintains his quality level at the required minimum standard while the big country's producer reduces his quality level. The overall effect of market integration is thus a decrease of the quality level in the industry, but for both countries the welfare implications are ambiguous, dependent on the parameters of the model.

The paper is organized as follows. Section 2 presents the basic assumptions and notation of the model. Section 3 derives the price and quality equilibrium on the two partially segmented markets. The effects of market integration are analyzed by comparing the equilibrium for alternative sizes of trade costs. Section 4 analyses the effects of market integration when a common minimum quality standard is introduced. Section 5 discusses the effects of market integration and quality regulation on welfare. Section 6 concludes.

\section{The Model}

The world consists of two countries, 1 and 2, with one producer of a 
differentiated product in each. The products are differentiated both vertically and horizontally. Vertically, the quality of the product is characterised by a quality indicator $\theta(\theta \geq 0)$. In the horizontal dimension, each consumer has an address or ideal variant characterised by $x$, where $x=[0,1]$. Each consumer is assumed to consume one unit only of the differentiated good. The consumer chooses the variant, which offers the largest utility gain, given by the gross utility of consuming the good minus the costs of acquiring it. These costs consist of the price at the gate of the producer plus trade costs, in case the consumer prefers the foreign good. The consumers in each country are uniformly distributed with respect to $x$ in the interval 0 to 1 . However, the two countries might be asymmetrical in size. The number of consumers is normalized to 1 in country 1 and to $\sigma$ in country 2 , and throughout in the following analysis, it is assumed that $\sigma \geq 1$.

The producer's horizontal position is exogenously given contrary to the vertical position, where the quality level is a strategic variable. Horizontally, the producers are assumed to have opposite endpoint locations, so the country 1 based firm is located at 0 while the country 2 based firm is located at 1 ; however the production plant of each firm is located within the territorial boundary of the respective country. ${ }^{1}$ Hence, for a consumer at the address $x$, the horizontal distance to the producer in country 1 is $x$ and $(1-x)$ to the producer in country 2, respectively. However, if the consumer demands the foreign good, he incurs trade costs at $g$ per unit. Although the markets are partially segmented by trade costs, it is assumed impossible for the producer to distinguish between domestic and foreign buyers. Each producer therefore charges a uniform price i.e. price discrimination is neglected.

For the consumer in country 1, the utility of consuming one unit of the good produced by the domestic or by the foreign producer respectively is given by the additive separable specification of the vertical and horizontal dimensions: ${ }^{2}$

$$
u_{11}=v+\theta_{1}-t x-p_{1}
$$

\footnotetext{
${ }^{1}$ D'Aspremont et al. (1979) have shown that two producers choose maximal horizontal distance at the market, if the transport cost or utility loss is a quadratic function of distance. However, in the following we use linear distance costs.

${ }^{2}$ The additive specification of quality in the utility function has been suggested by Mussa and Rosen (1978) and has later been used in several analyses e.g. Tirole (1988). Another specification of quality in the utility function is to use a multiplicative specification, where basic utility depends on consumption of other (non-differentiated) goods, which varies proportionately with the quality indicator of the differentiated good. This alternative specification has been introduced by Gabszewicz and Thisse (1979) and later used by Shaked and Sutton (1982) and Boom (1995), among others.
} 
and

$$
u_{12}=v+\theta_{2}-t(1-x)-p_{2}-g
$$

For a consumer in country 2 , the utility of consuming one unit of the foreign good or alternatively the domestic good is given by:

and

$$
u_{21}=v+\theta_{1}-t x-p_{1}-g
$$

$$
u_{22}=v+\theta_{2}-t(1-x)-p_{2}
$$

where $v$ is an exogenously given parameter, $t$ a parameter for the loss of utility per unit increase in the horizontal distance between a consumer and a producer, $p$ prices obtained by producers and $g$ trade cost. ${ }^{3}$ We assume that the consumer's attachment to the preferred variant measured by the size of the parameter $t$ is strong. As appears from the following formal analysis, this assumption secures that qualities are strategic substitutes for the two companies.

The producers are assumed to share the same technology and hence, to be symmetrical with respect to cost effectiveness. The variable unit costs are assumed to be independent of quality and constant with respect to quantity produced. Quality is output from the firm's R\&D activity. To develop quality the firm incurs sunk costs. The flow equivalent fixed costs to the sunk costs for the firm is assumed to be a quadradic function of quality, i.e. the cost functions for the two producers are specified by (2):

$$
C_{i}=c Q_{i}+\frac{1}{2} \theta_{i}^{2} \quad i=1,2
$$

where $Q_{i}(\mathrm{i}=1,2)$ is the quantity of the good produced by the two producers and $c$, variable unit costs.

The model specified above is similar to that of Garella $(2003,2006)$, but

\footnotetext{
${ }^{3}$ The specification of the utility function disregards diversity of tastes with respect to quality. In most other papers in this tradition, the effect on utility of quality in the individual utility function is assumed to depend both on a good specific indicator of quality and a consumer specific parameter related to the weight the consumer puts on quality, see e.g. Tirole (1988).
} 
extended by including two partially segmented markets.

\section{Equilibrium in Unregulated Markets}

This section deals with unregulated markets where no quality requirements by governments have been imposed. The producers use the quality level and price as strategic variables. It is assumed that each producer in a first-stage game chooses his quality level and subsequently chooses price in the second-stage game. The Nash equilibrium is derived by backward induction i.e. by deriving the prices for given qualities, and then determination of qualities.

To simplify, we assume that the two markets are fully covered i.e. each consumer in both countries buys one unit of the good. This will be the case for sufficient large values of the utility parameter $v$. On a given market, a competitive edge exists between the two producers defined as the location of a marginal consumer, who is indifferent whether to buy the variant from one or the other producer. In country 1 , the competitive edge $\tilde{x}_{1}$ is determined by:

$$
v+\theta_{1}-t x-p_{1}=v+\theta_{2}-t(1-x)-p_{2}-g
$$

which gives:

$$
\tilde{x_{1}}=\frac{1}{2 t}\left[t+\left(p_{2}-p_{1}+g\right)+\left(\theta_{1}-\theta_{2}\right)\right]
$$

Similarly, the competitive edge in country 2 is given by:

$$
\tilde{x}_{2}=\frac{1}{2 t}\left[t+\left(p_{2}-p_{1}-g\right)+\left(\theta_{1}-\theta_{2}\right)\right]
$$

Total demand for product 1 and $2, \mathrm{Q}_{1}$ and $\mathrm{Q}_{2}$, respectively, is given by:

$$
\begin{aligned}
Q_{1} & =\tilde{x}_{1}+\sigma \tilde{x}_{2} \\
& =\frac{1}{2 t}\left[(1+\sigma) t+(1+\sigma)\left(p_{2}-p_{1}\right)-(\sigma-1) g+(1+\sigma)\left(\theta_{1}-\theta_{2}\right)\right]
\end{aligned}
$$

and:

$$
\begin{aligned}
Q_{2} & =\left(1-\tilde{x}_{1}\right)+\sigma\left(1-\tilde{x_{2}}\right) \\
& =\frac{1}{2 t}\left[(1+\sigma) t-(1+\sigma)\left(p_{2}-p_{1}\right)+(\sigma-1) g-(1+\sigma)\left(\theta_{1}-\theta_{2}\right)\right]
\end{aligned}
$$


Profits, $\pi_{i}$, for the two producers are given by:

$$
\pi_{1}=\left(p_{i}-c\right) Q_{i}-\frac{1}{2} \theta_{i}^{2} ; i=1,2
$$

\section{A. Price equilibrium}

The producers are assumed to play Bertrand and hence maximize profit with respect to the price of the producer's own product, given the price of the competitor's product and qualities. Inserting (4a) and (4b) in (5) and maximizing each producer's profit with respect to his own price, gives the following price reaction functions for the producer in country 1 and 2, respectively:

$$
\begin{aligned}
& p_{1}=\frac{1}{2}\left[p_{2}-\frac{(\sigma-1) g}{(1+\sigma)}+\left(\theta_{1}-\theta_{2}\right)+(t+c)\right] \\
& p_{2}=\frac{1}{2}\left[p_{1}+\frac{(\sigma-1) g}{(1+\sigma)}-\left(\theta_{1}-\theta_{2}\right)+(t+c)\right]
\end{aligned}
$$

Solving (6a) and (6b) with respect to prices gives Bertrand equilibrium:

$$
p_{1}=\frac{1}{3}\left[-\frac{(\sigma-1) g}{(1+\sigma)}+\left(\theta_{1}-\theta_{2}\right)+3(t+c)\right]
$$

and:

$$
p_{2}=\frac{1}{3}\left[\frac{(\sigma-1) g}{(1+\sigma)}-\left(\theta_{1}-\theta_{2}\right)+3(t+c)\right]
$$

Using (7a) and (7b) in (4a) and (4b) gives the quantity demanded or output in equilibrium:

$$
Q_{1}=\frac{1}{6 t}\left[3(1+\sigma) t-(\sigma-1) g+(1+\sigma)\left(\theta_{1}-\theta_{2}\right)\right]
$$

and:

$$
Q_{2}=\frac{1}{6 t}\left[3(1+\sigma) t+(\sigma-1) g-(1+\sigma)\left(\theta_{1}-\theta_{2}\right)\right]
$$

The results above illustrate the role of qualities for prices and output for the two 
companies. If one of the companies, say company 1 , raises the quality of its product, the company will charge a higher price, but the price increase will only partly match the quality increase in the consumers' eyes. Hence, company 1 increases its market share on behalf of company 2, which will lower its price to mitigate the pressure on its market share. Output will thus increase for company 1 , but decrease for company 2. The horizontal preferences represent the degree of loyalty of the individual consumers to the product from either company 1 or 2 . Strong horizontal preferences therefore allow for high prices relative to variable unit costs, see (7a) and (7b). For similar reasons the effects on market share (output) of an increase in quality of one of the companies' products is more modest in case of strong horizontal preferences.

\section{B. Choice of quality}

The results (7a), (7b), (8a) and (8b) allow us to deal with the first-stage game: determination of quality levels. Profits in the Bertrand equilibrium are given by (5). Maximizing $\pi_{1}$ with respect to $\theta_{1}$ and $\pi_{2}$ with respect to $\theta_{2}$ by using (7a), (7b), (8a) and $(8 b)$ gives the quality reaction function for the producer in country $1\left(\mathrm{R}_{1}\right)$ and country $2\left(\mathrm{R}_{2}\right)$, respectively:

$$
\begin{aligned}
& \theta_{1}=\frac{1}{(9 t-(1+\sigma))}\left[-(1+\sigma) \theta_{2}-(\sigma-1) g+3(1+\sigma) t\right] \\
& \theta_{2}=\frac{1}{(9 t-(1+\sigma))}\left[-(1+\sigma) \theta_{1}+(\sigma-1) g+3(1+\sigma) t\right]
\end{aligned}
$$

Figure 1 illustrates the quality reaction functions $R_{1}$ and $R_{2}$ and the resulting Nash equilibrium A.

The quality reaction functions are negatively sloped i.e. qualities are strategic substitutes. This is only the case when the horizontal preferences are relatively strong i.e. $t$ exceeds $(1+\sigma) / 9$. The intuition behind this feature follows from the effects on market share of quality changes. As previously noticed if one of the companies increases its product quality it captures a larger market share on behalf of the other company. The smaller market left for the other company induces this company to lower the quality of its product to reduce development costs of quality.

In case the horizontal preferences are relatively weak, the return of a quality improvement is larger, since the quality increase will attract relatively more consumers from the other producer. In such cases the high quality producer may 
Figure 1. Quality reaction functions and Nash equilibrium

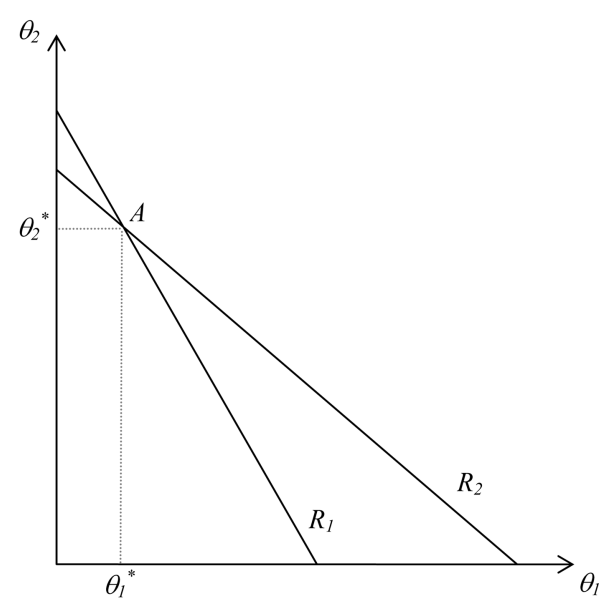

persistently get more profit by raising his quality and the low quality producer may gain by lowering his quality and hence, the outcome will be maximum quality differentiation. ${ }^{4}$ This result is similar to the extreme case of pure vertical product differentiation in the model of Gabszewicz and Thisse (1979).

Solving (9a) and (9b) gives the quality levels in Nash equilibrium:

$$
\begin{aligned}
& \theta_{1}^{*}=\frac{(1+\sigma)}{3}-\frac{(\sigma-1)}{(9 t-2(1+\sigma))} g \\
& \theta_{2}^{*}=\frac{(1+\sigma)}{3}+\frac{(\sigma-1)}{(9 t-2(1+\sigma))} g
\end{aligned}
$$

The quality levels of the two producers are different apart from the special case where trade costs $(g)$ are zero.

The prices and output in Nash equilibrium are derived by inserting (10a) and (10b) into (7a) - (8b). This gives:

$$
\begin{aligned}
& p_{1}^{*}=t+c-\frac{3(\sigma-1) t}{(1+\sigma)(9 t-2(1+\sigma))} g \\
& p_{2}^{*}=t+c+\frac{3(\sigma-1) t}{(1+\sigma)(9 t-2(1+\sigma))} g
\end{aligned}
$$

${ }^{4}$ See appendix A for a further explanation. 


$$
\begin{aligned}
Q_{1}^{*} & =\frac{1}{2}\left[(1+\sigma)-\frac{3(\sigma-1)}{(9 t-2(1+\sigma))} g\right] \\
& =\frac{3}{2} \theta_{1}^{*}
\end{aligned}
$$

and:

$$
\begin{aligned}
Q_{2}^{*} & =\frac{1}{2}\left[(1+\sigma)+\frac{3(\sigma-1)}{(9 t-2(1+\sigma))} g\right] \\
& =\frac{3}{2} \theta_{2}^{*}
\end{aligned}
$$

Using these results, the profits in Nash equilibrium for the two companies are given by:

$$
\begin{aligned}
\pi_{1}^{*} & =\left(p_{1}^{*}-c\right) Q_{1}^{*}-\frac{\theta_{1}^{* 2}}{2} \\
& =\frac{9 t-(1+\sigma)}{18(1+\sigma)}\left[-\frac{3(\sigma-1)}{(9 t-2(1+\sigma))} g+(1+\sigma)\right]^{2} \\
& =\frac{(9 t-(1+\sigma))}{2(1+\sigma)} \theta_{1}^{* 2} \\
\pi_{2}^{*} & =\left(p_{2}^{*}-c\right) Q_{2}^{*}-\frac{\theta_{2}^{* 2}}{2} \\
& =\frac{9 t-(1+\sigma)}{18(1+\sigma)}\left[\frac{3(\sigma-1)}{(9 t-2(1+\sigma))} g+(1+\sigma)\right]^{2} \\
& =\frac{(9 t-(1+\sigma))}{2(1+\sigma)} \theta_{2}^{* 2}
\end{aligned}
$$

Given the assumed strong horizontal preferences, both firms earn positive profits and the rank of profits coincides with the rank of qualities.

The producer on the large market delivers the variant with the highest quality. Quality requires fixed costs, and easy access to the large market therefore gives this producer a competitive advantage in quality development relative to the producer located on the small market. For the same reason, price and output are also larger for the producer on the large market compared with the producer on the small market. Since the two countries are exchanging products within the same industry, 
we observe in equilibrium intra-industry trade in vertically differentiated products, but at the same time also an exchange of products that are differentiated horizontally. Disentangling intra-industry trade into a horizontal and a vertical part is thus problematic. ${ }^{5}$

\section{Market integration}

The model allows for an examination of the effects on qualities, prices and output levels of economic integration i.e. a decrease of trade costs, g. For $\sigma>1$ it follows from (10a)-(13b) that:

$$
\frac{\partial \theta_{1}^{*}}{\partial g}, \frac{\partial p_{1}^{*}}{\partial g}, \frac{\partial Q_{1}^{*}}{\partial g}, \frac{\partial \pi_{1}^{*}}{\partial g}<0
$$

and:

$$
\frac{\partial \theta_{2}^{*}}{\partial g}, \frac{\partial p_{2}^{*}}{\partial g}, \frac{\partial Q_{2}^{*}}{\partial g}, \frac{\partial \pi_{2}^{*}}{\partial g}>0
$$

Figure 2 illustrates the effect on quality of a decrease in trade costs.

The relative advantage of being located on the large market weakens, when trade costs decrease. Qualities, prices and output levels therefore converge between the two countries, when market integration is deepened.

\section{Minimum Quality Standards}

We now assume that the two countries introduce a common minimum quality standard $\bar{\theta}$. The reason for introducing the minimum standard may be a common belief in the countries that producing a product below a given level of "quality"

${ }^{5}$ In empirical trade studies on intra-industry trade disentangling trade in horizontally and vertically differentiated products, the dominant methodology has been to divide a given product group into either horizontal or vertical intra-industry trade by comparing unit values for exports and imports, see e.g. Greenaway et al. (1994). Within many product groups (or industries) there may at the same time be trade in horizontally as well as vertically differentiated goods between countries. Look e.g. at trade in cars between Germany and South Korea. On average, it is reasonable to assume that German cars are of a higher quality than Korean cars. But at the same time, there may be a number of Korean producers producing car models at a similar quality level from which German consumers may choose depending on their preferences (ideal variants in Lancaster terms). There seems therefore to be good reason in trade theory to combine the horizontal and vertical dimension in product differentiation as is done in our model. This may open up for better empirical studies on intra-industry trade. 
Figure 2. Market integration and product qualities on the unregulated markets

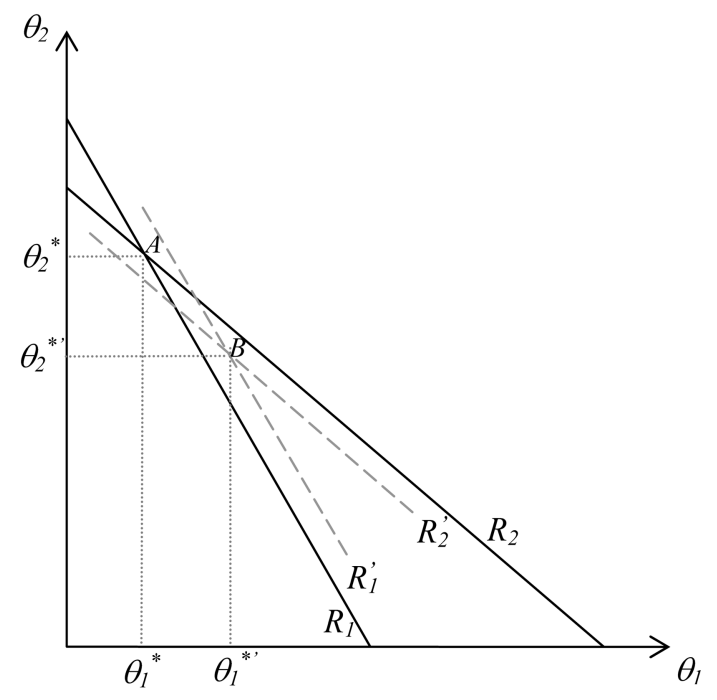

creates a health or an environmental risk for the consumers. It is assumed that $\theta_{1}^{*}<\bar{\theta}<\theta_{2}^{*}$ i.e. the minimum quality standard will force the low quality producer to raise the quality of his product. However, the compulsory change of the product quality of the low quality producer will induce the high quality producer to change his quality too. As qualities are strategic substitutes, the high quality producer will be induced to reduce his quality. Formally, this follows from inserting $\theta_{1}=\bar{\theta}>\theta_{1}^{*}$ into (9b) which gives:

$$
\hat{\theta}_{2}=\frac{1}{(9 t-(1+\sigma))}[-(1+\sigma) \bar{\theta}+(\sigma-1) g+3(1+\sigma) t]
$$

This can be compared with the quality level in Nash equilibrium in the unregulated market, $\theta_{2}^{*}$, given by $(9 \mathrm{~b})$ for, $\theta_{1}=\theta_{1}^{*}$ i.e.:

$$
\hat{\theta}_{2}=\frac{(1+\sigma)}{(9 t-(1+\sigma))}\left(\bar{\theta}-\theta_{1}^{*}\right)+\theta_{2}^{*}<\theta_{2}^{*}
$$

Graphically, the impacts of implementation of a minimum quality standard on quality levels are illustrated in Figure 3.

The Nash Equilibrium is illustrated by the set of qualities in A. Implementation of a minimum quality standard changes equilibrium to $\mathrm{C}$. The minimum quality 
Figure 3. Impact of a minimum quality standard

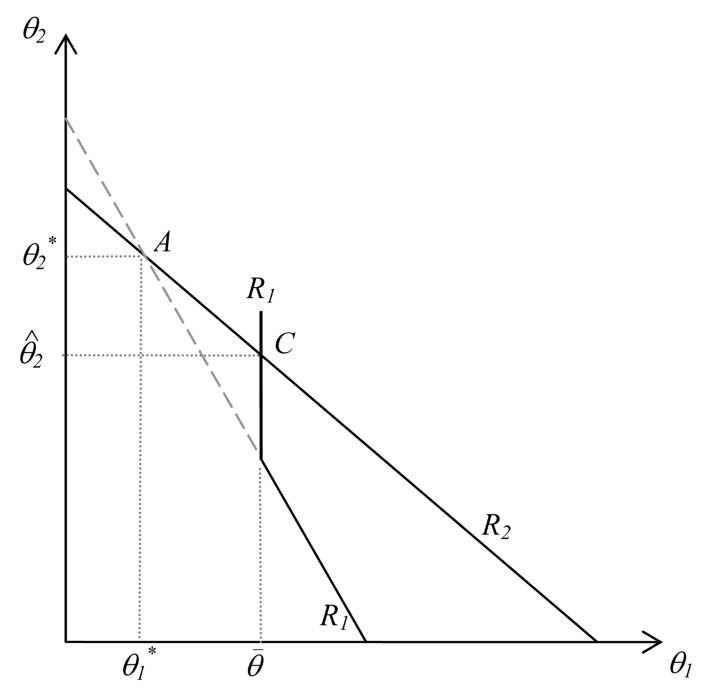

standard can be perceived as a Stackelberg game, where the low quality producers (involuntarily) become Stackelberg leader, leaving the role of Stackelberg follower to the high quality producer.

Prices, output levels and profits follow from inserting $\theta_{1}=\bar{\theta}$ and $\theta_{2}=\hat{\theta}_{2}$ into (7a), (7b), (8a), (8b) and (5). Inspection of the results reproduced in appendix B shows that:

$$
\frac{\partial \hat{p}_{1}}{\partial \bar{\theta}}, \frac{\partial \hat{Q}_{1}}{\partial \bar{\theta}}>0
$$

and:

$$
\frac{\hat{\partial} \hat{p}_{2}}{\partial \bar{\theta}}, \frac{\partial \hat{Q}_{2}}{\partial \bar{\theta}}<0
$$

The compulsory increase of the quality level for the low quality producer raises his price and output level, but lowers the price and output level of the high quality producer. The effects on profits are more complicated to analyze, but may easily be captured by a graphical analysis of the iso-profit curves in quality space, see Figure 4.

Basically it should be noticed that each of the producers' profit varies inversely with the quality level of the competitor's product along the quality reaction function. Implementation of a minimum quality standard therefore unambiguously reduces 
Figure 4. Minimum quality standards and profits

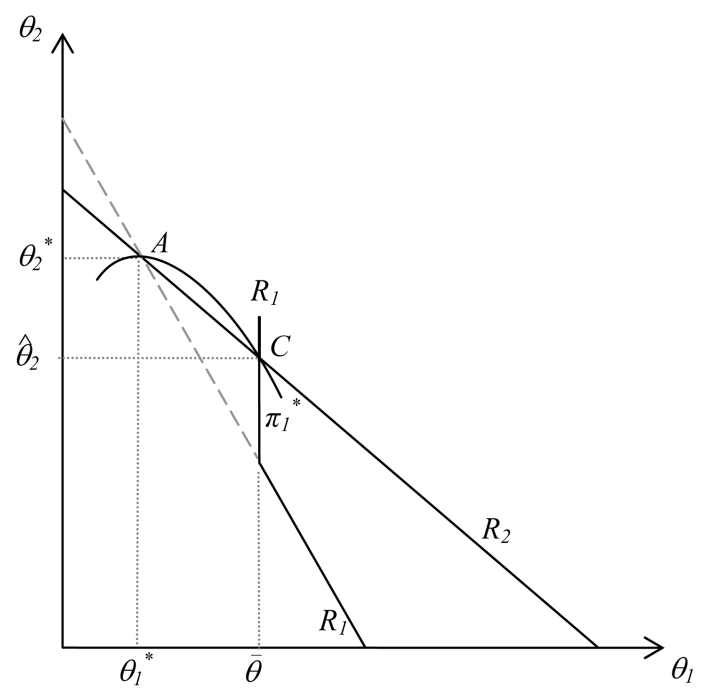

the profit of the high quality producer; see the movement from the unregulated equilibrium $\mathrm{A}$ to the regulated equilibrium $\mathrm{C}$ in Figure 4. The effect on the profit for the low quality producer is ambiguous. Figure 4 illustrates the special case where the size of the minimum quality standard leaves the profit of the low quality producer unaffected. It follows straight forward that in more general cases $\pi_{1}$ (profit with minimum quality standard) exceeds $\pi_{1}^{*}$ (profit without) for all isoprofit curves for producer 1 , which cut or are tangent to $\mathrm{R}_{2}$ in the interval between $\theta_{1}^{*}$ and $\bar{\theta}$. A mild minimum quality standard close to the unregulated quality level of the low quality producer thus raises his profit, contrary to a severe minimum quality standard, which will harm the profit of the low quality producer. ${ }^{6}$

\section{Market integration}

The model also allows for an analysis of the effects of market integration, i.e. a decrease of $g$, in case of an existing minimum quality standard. From (14) and the results in Appendix B, we have for modest changes in the trade barrier $(g)$ :

\footnotetext{
${ }^{6}$ The profit of the low quality producer is maximized for a minimum quality standard $\bar{\theta}_{\max }$ (not illustrated) where the iso-profit curve of the producer in the small country is tangent to the quality reaction function of the producer from the large, i.e. $\bar{\theta}_{\max }$ establishes the Stakelberg solution if the low quality producer acted as quality-leader in the strategic game. In the case illustrated in Figure 4 $\theta_{1}^{*}<\bar{\theta}_{\max }<\bar{\theta}$.
} 


$$
\frac{\partial \hat{\theta}_{1}}{\partial g}=0 ; \frac{\partial \hat{p}_{1}}{\partial g}, \frac{\partial Q_{1}}{\partial g}<0
$$

and:

$$
\frac{\partial \hat{\theta}_{2}}{\partial g}, \frac{\partial \hat{p}_{2}}{\partial g}, \frac{\partial Q_{2}}{\partial g}>0
$$

Market integration will reduce the quality of the product of the high quality producer, but leave quality unchanged for the low quality producer, as he is forced to produce to the minimum standard. The overall effect is thus unambiguously a decrease of average product quality on the market. This is in contrast to the unregulated case, where the effects of market integration on quality levels are ambiguous as the low quality producer increases its quality while the high quality firm reduces its quality.

Figure 5 illustrates the effects of market integration, when the markets are initially regulated. The decrease of the trade barrier moves the reaction curve of the high quality producer inwards from $\mathrm{R}_{2}$ to $\mathrm{R}_{2}{ }^{\prime}$ and the segment of the reaction curve of the low quality producer outwards from $R_{1}$ to $R_{1}$. If the decline of trade costs is relatively modest, the minimum quality standard will still be binding for the low quality producer and equilibrium changes from $\mathrm{C}$ to $\mathrm{C}$.

Figure 5. Market integration and minimum quality standard

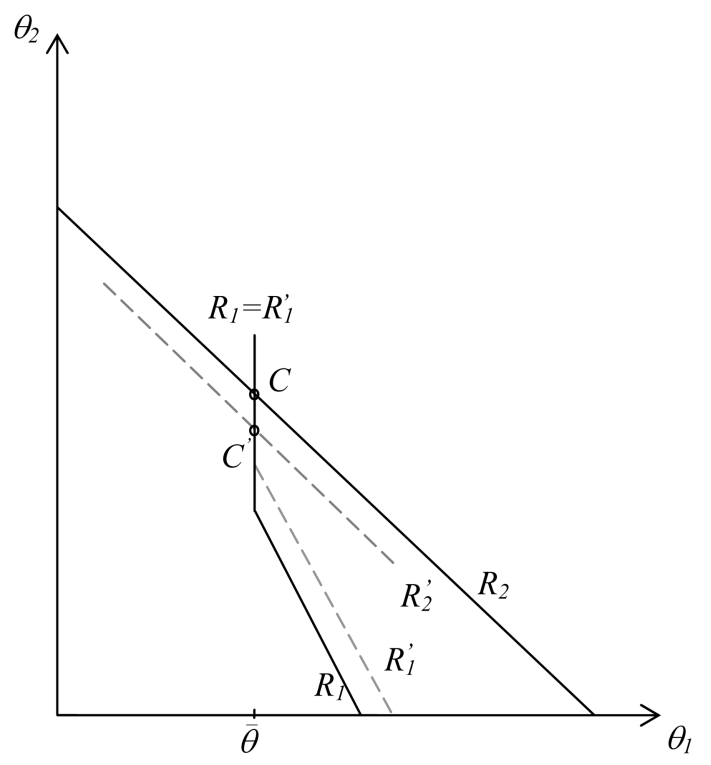


The decrease of the trade barrier and the induced effects of this on the quality of the high quality producer increase the price and the output level of the low quality producer, but decrease the price and the output level of the high quality producer.

It is interesting to notice that a minimum quality standard and market integration both influence the qualities of the two products in the same direction. Thus liberalisation of trade restrictions reduces the need for minimum standards and in that sense trade liberalisation and minimum quality standards are policy substitutes. However, the two policies differ in relative impacts on qualities. If the policy maker has the goal to raise quality of the low quality producer to $\bar{\theta}$, see Figure 5 , trade policy liberalisation results in a lower quality level of the high quality good compared with a minimum quality standard.

\section{Welfare Implications}

This section deals with the welfare implications of market integration and minimum quality standards. Welfare $W_{i}$ consists of producer surplus $\pi_{i}$ and total consumer surplus $C S_{i}$, i.e. consumer surplus for all individuals in the country consuming either the domestically or the foreign produced good: ${ }^{7}$

$$
W_{i}=\pi_{i}+C S_{i} ; \mathrm{i}=1,2
$$

As shown in the following, the welfare effects of market integration as well as quality regulation are in general ambiguous.

\section{A. Market integration}

Market integration increases welfare in the special case where both countries are of equal size. Qualities, prices at firm gate, output levels and profits are in this case independent of the trade barrier; see (10a) - (13b) for $\sigma=1$, which imply $\theta_{1}{ }^{*}=\theta_{2}{ }^{*}$ $=2 / 3$ and $p_{1}{ }^{*}=p_{2}{ }^{*}=(t+c)$. However, the consumers in each country, who buy the foreign produced good, or who switch to the foreign good, experience an increase in utility as the price for those consumers has decreased. As this is the only welfare

\footnotetext{
${ }^{7}$ The following welfare analysis only deals with (private) consumer and producer welfare and hence, different types of externalities are disregarded. This is at odds with the argument that quality regulation is typically motivated by externalities related to health and safety effects of specific production and consumption activities. Moreover the analysis only deals with real trade costs i.e. there are no public budget effects.
} 
effect, total welfare increases.

In the more general case of asymmetric country sizes, market integration impacts both profit and consumer surplus. The effects on profits follow straight forward from the different market sizes. A decrease of trade costs raises the profit for the producer in the small country, but lowers the profit for the producer in the large country, see (13a) and (13b) for decreasing $g$. The producer in the small country benefits from getting better access to the large foreign market and this benefit exceeds the loss from the more keen competition on the small domestic market. The producer in the large country faces the opposite changes in his competitive situation and is therefore net loser.

The effects on consumer surplus are more complicated to figure out as market integration affects the consumers differently depending on whether the consumer buys the domestically or the foreign produced good. First, it should be noted that a decrease of trade costs lowers directly the consumer price of the foreign produced good. However, indirect effects exist as the decrease of trade costs translates into prices at firm gates and quality levels through the strategic game between the producers and hence, in general all consumers are affected.

The utility of the consumers in country 1 , who buy the domestically or the foreign produced good respectively appears from inserting prices and qualities in the Nashequilibrium given by (10a) to (11b) into the utility functions (1a) and (1b). Taking the first-order derivative of these utilities with respect to $g$ gives the following expressions (17a) and (17b) for the effects of market integration on utility for the two groups of consumers: ${ }^{8}$

$$
\begin{gathered}
-\frac{\partial u_{11}^{*}}{\partial g}=-\frac{\partial \theta_{1}^{*}}{\partial g}+\frac{\partial p_{1}^{*}}{\partial g}=\frac{(1+\sigma-3 t)(\sigma-1)}{(1+\sigma)[9 t-2(1+\sigma)]} \\
-\frac{\partial u_{12}^{*}}{\partial g}=-\frac{\partial \theta_{2}^{*}}{\partial g}+\frac{\partial p_{2}^{*}}{\partial g}+1=\frac{(1+\sigma-3 t)(\sigma-1)}{(1+\sigma)[9 t-2(1+\sigma)]}+1
\end{gathered}
$$

Adding (17a) and (17b) gives for country 1 :

$$
-\frac{\partial u_{11}^{*}}{\partial g}-\frac{\partial u_{12}^{*}}{\partial g}=1
$$

\footnotetext{
${ }^{8}$ The following analysis concentrates on consumers, who both before and after the decrease in trade costs, consume either the domestically or the foreign produced good. We thus disregard the utility effects from consumers who switch between domestically and foreign produced goods. Since this group is small relatively to the group of loyal consumers its effects on consumers surplus is marginal.
} 
Similarly we have for country 2 :

$$
-\frac{\partial u_{21}^{*}}{\partial g}-\frac{\partial u_{22}^{*}}{\partial g}=1
$$

The relations (18a) and (18b) show for each country a trade-off between the utility effects for two consumers, who consume either the domestically or the foreign produced good. The sum of the utility effects for these two consumers make up one, which is the partial utility effect of a decrease of trade costs for a consumer buying the foreign good for given prices at firm gate and given qualities. It follows from (17a) and (17b) that the utility effect for one of the consumers from one of the groups may even be negative.

The effect of market integration on consumer surplus at country level appears as the sum of the utility effects for all individual consumers. Hence, consumer surplus of the country depends both on the utility effect of the individual consumer and on the distribution of all consumers between the two groups. The distribution of consumers depends crucially on the level of trade costs.

In case one of the two groups of consumers in a country suffers a loss of utility because of a decrease of trade costs, the effect on consumer surplus may be negative for that country if the number of losers is sufficiently large compared with the number of winners. The overall conclusion is therefore that the total effect on welfare in some cases may be negative in one of the countries. The risk of a negative welfare effect is largest for the large country, where the effect on producer surplus (profit) is negative.

\section{B. Minimum quality standards}

The conclusions about the welfare effects of minimum quality standards are also ambiguous for both countries. As noticed previously, profit for the producer in the large country decreases unambiguously when a minimum quality standard is introduced. For the producer in the small country the effect on profit is ambiguous. A mild quality regulation raises profit for the producer in the small country while a stern regulation may reduce profit for this producer.

The effect of a quality restriction on consumer surplus is ambiguous in both ${ }^{9}$ In the special case of equal sized markets $-\frac{\partial u_{11}^{*}}{\partial g}=-\frac{\partial u_{22}^{*}}{\partial g}=0$ and $-\frac{\partial u_{12}^{*}}{\partial g}=-\frac{\partial u_{21}^{*}}{\partial g}=1$, i.e. only
consumers who prefer the foreign produced good benefit from market integration. 
countries. This follows again from inspection of the effects on consumer surplus of the individual consumer consuming the domestically or the foreign produced good, respectively. Using (1a) - (1b), (15) and (B.1a) and (B.1.b) in appendix B, the effects of a marginal increase of the minimum quality standard on consumer surplus for consumers buying the good produced in country 1 and country 2 respectively are given by:

$$
\begin{gathered}
\frac{\partial \hat{u}_{11}}{\partial \bar{\theta}}=\frac{\partial \hat{u}_{21}}{\partial \bar{\theta}}=1-\frac{\partial \hat{p}_{1}}{\partial \bar{\theta}}=\frac{6 t-(1+\sigma)}{(9 t-(1+\sigma)} \\
\frac{\partial \hat{u}_{12}}{\partial \bar{\theta}}=\frac{\partial \hat{u}_{22}}{\partial \bar{\theta}}=1-\frac{\partial \hat{\theta}_{2}}{\partial \bar{\theta}}-\frac{\partial \hat{p}_{2}}{\partial \bar{\theta}}=\frac{3 t-(1+\sigma)}{(9 t-(1+\sigma)}
\end{gathered}
$$

The sign of these effects for the individual consumers depends on the values of the parameters. The effect on consumer surplus at country level in each of the two countries is therefore ambiguous and so is the total welfare effect.

\section{Conclusions}

This paper analyzes the effects of market integration on product qualities in a two country duopoly model with one producer located in each country. The products are both vertically and horizontally differentiated, and the producers perceive qualities as strategic variables. The markets are segmented by real trade costs so each producer has a competitive advantage on his domestic market. Development of quality requires fixed costs and hence, scale economies exist. Because of different market sizes an asymmetry is introduced in the model.

Market equilibrium is derived both in the case of no quality regulation and in the case of a common minimum quality standard. Because of scale economies related to quality, country size matters, so the large country will develop and produce high quality products relative to the products from the small country. Market integration weakens this advantage for the producer on the large market. On the unregulated market the high quality producer therefore reduces the quality of his product, while the low quality producer raises the quality of his product. In the case where a common minimum quality standard forces the low quality producer from the small country to increase the quality level, the producer from the large country reacts strategically by lowering the quality level of his product. Furthermore, it is shown 
that the incentive to reduce quality for the high quality producer in case of market integration also exists in case that a common minimum standard binds the quality level of the low quality producer to the minimum standard. The welfare implications of market integration and implementation of a minimum quality standard are also discussed in the paper. Both consumers and producers may be affected differently and this in general leaves the total welfare effects of market integration and a minimum quality standard ambiguous.

The main conclusion that market sizes matter also has relevance for the impacts on qualities of establishing a regional bloc such as e.g. the European Union. Creating a large internal market free of trade barriers between a subset of countries will transform these individually small markets to one big market. This will stimulate quality development for firms located here. In contrast, firms located in third party countries react by lowering the qualities of their products.

There are obvious routes for extending the analysis. The rationale for a minimum quality standard should probably be found in various externalities e.g. related to health and safety effects from production or consumption. This points to the need of a broader welfare analysis. Another generalization would be to include the government's policy endogenously in the analysis. Both market integration and quality regulation have distributional effects on profits and welfare for the two countries. Given the governments' objective functions, the governments may enter into the game by making decisions on market integration or implementation of national minimum quality standards.

\section{Appendix A. The quality reactions function}

To derive the quality reaction function for e.g. producer 1, the Bertrand solution (7a) and (8a) is inserted in (5). This gives:

$$
\pi_{1}=\left(p_{1}-c\right) Q_{1}-\frac{1}{2} \theta_{1}^{2}=\frac{1}{18 t(1+\sigma)}\left[-(\sigma-1) g+(1+\sigma)\left(\theta_{1}-\theta_{2}\right)-3 t(1+\sigma)\right]^{2}-\frac{1}{2} \theta_{1}^{2}
$$

The first term on the right hand side represents (net)revenue or operating profit and the second, fixed costs caused by quality development. 
Maximum perceived profit exists for the quality level where $\partial \pi_{1} / \partial \theta_{1}=0$ if $\partial \pi_{1}^{2} /$ $\partial \theta_{1}^{2}<0$. From (A1) we have:

$$
\partial \pi_{1} / \partial \theta_{1}=1 / 9 t\left[-(\sigma-1) g+(1+\sigma)\left(\theta_{1}-\theta_{2}\right)-3 t(1+\sigma)\right]-\theta_{1}
$$

where the first term on the right hand side is marginal (net)revenue, $M R \theta_{l}$, and the second term marginal costs, $M C \theta_{l}$, both with respect to quality.

Figure A1 illustrates the $M C \theta_{l}$ - and $M R \theta_{l}$-curves (for two alternative values of $\left.\theta_{2}\right)$. The $M C \theta_{1}$-curve has the slope 1 and the $M R \theta_{1}$ the slope $(1+\sigma) / 9 t$. The producer maximizes perceived profit for the quality level where $M C \theta_{I}=M R \theta_{1}$, if the second order condition is fulfilled, i.e. if the $M R \theta_{l}$-curve, as in the illustrated case, is flatter than the $M C \theta_{1}$-curve.This gives the condition for a stable equilibrium $t>(1+\sigma) / 9$, i.e. the horizontal preference should be relatively strong.

If $\theta_{2}$ increases from $\theta_{2}{ }^{0}$ to $\theta_{2}{ }^{1}$, the $M R \theta_{1}$-curve shifts downwards, and to maximise profits, producer 1 therefore reduces his quality. Hence, the quality reaction curve is negatively sloped. Notice, that the producer is worse off, when the competitor raises the quality of his product (see A1), i.e. the producer's profit varies inversely with the quality of the competitor's products along the producer's quality reaction curve.

If horizontal preferences are relatively weak $(t<(1+\sigma) / 9)$, the slope of the $M R \theta_{1^{-}}$ function is steeper than the $M C_{2 I}$-function, and the no stable equilibrium exists.

Figure A1. Quality optimization of producer 1

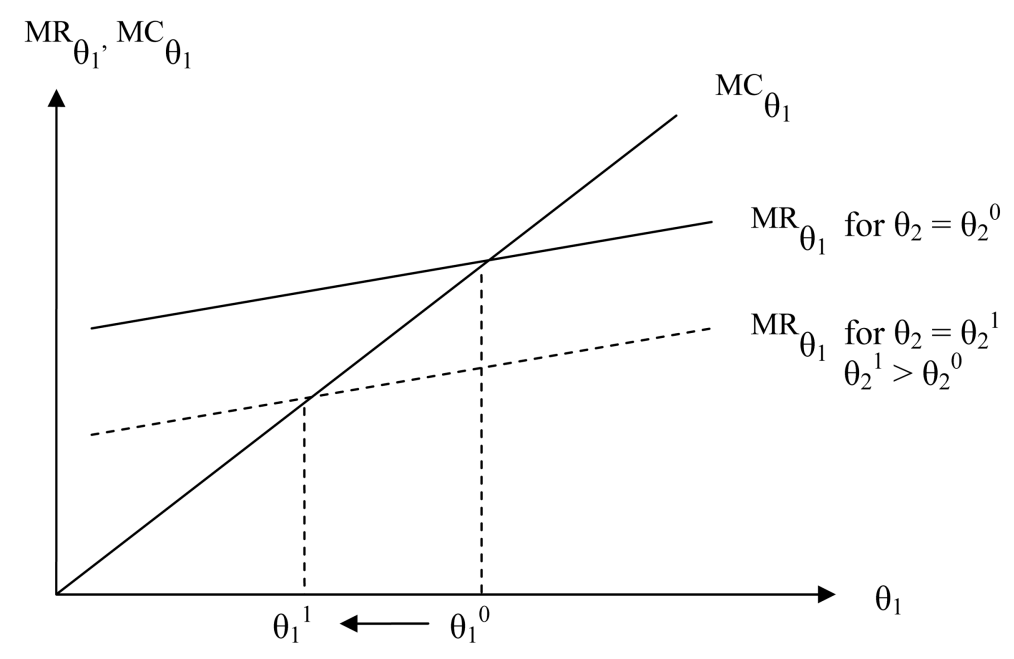




\section{Appendix B. Minimum quality standards, prices and output levels}

Inserting $\theta_{1}=\bar{\theta}$ and $\theta_{2}=\hat{\theta}$ given by (14) into (7a) and (7b) gives the prices on the regulated market:

$$
\begin{gathered}
\hat{p}_{1}=-\frac{(\sigma-1)}{3(1+\sigma)} g+\frac{\left(\bar{\theta}-\hat{\theta}_{2}\right)}{3}+t+c \\
=\frac{1}{(9 t-(1+\sigma))}\left[3 t \bar{\theta}-\frac{3 t}{(1+\sigma)} g+(9 t-2(1+\sigma)) t\right]+c \\
\hat{p}_{2}=\frac{(\sigma-1)}{3(1+\sigma)} g+\frac{\bar{\theta}-\hat{\theta}_{2}}{3}+t+c \\
=\frac{1}{(9 t-(1+\sigma))}\left[-3 t \bar{\theta}+-\frac{3 t}{(1+\sigma)} g-9 t^{2}\right]+c
\end{gathered}
$$

Note that $\hat{p}_{1}>p_{1}^{*}$ and $\hat{p}_{2}<p_{2}^{*}$ as $\theta_{1}^{*}<\bar{\theta}<\theta_{2}^{*}$, see (7a) and 7(b).

Received 3 September 2005, Accepted 11 July 2006

\section{References}

Boom, A. (1995) 'Asymmetric International Minimum Quality Standards and Vertical Differentiation', Journal of Industrial Economics, 43, 101-119.

Crampes, C. and A. Hollander (1995) 'Duopoly and Quality Standards', European Economic Review, 39, 71-82.

D'Aspremont, C, J. Gabszewicz, and J.-F. Thisse (1979) 'On Hotelling's Stability in Competition', Econometrica, 17, 1145-1151.

Gabszewicz, J. J. and J-F Thisse (1979) 'Price Competition, Qualities and Income Disparities' Journal of Economic Theory, 20, 340-359.

Garella, P. G., (2003) 'The Effects of Minimum Standards: Better or Worse Products?' WP 484, Department of Economics. Univerity of Bologna.

Garella, P. G., (2006) “ "Innocuous” Minimum Quality Standards'. Economics Letters. 92(3): 368-374

Greenaway, D.; R. Hine, and C. Milner (1994) 'Country-Specific Factors and the Pattern of Horizontal and Vertical Intra-Industry Trade in the UK', Weltwirtscahftliches Archiv 130(1), 77-100.

Lutz, S. H., (2000) 'Trade Effects of Minimum Quality Standards with and without Deterred Entry.' Journal of Economic Integration, 15(2), 314-344.

Mussa, M. and S. Rosen, (1978) 'Monopoly and Product Quality', Journal of Economic Theory, 18, 301-317. 
Ronnen, U., (1991) 'Minimum Quality Standards, Fixed Costs, and Competition', Rand Journal of Economics, 22, 490-504.

Shaked, A. and J. Sutton, (1982) 'Relaxing Price Competition Through Product Differentiation', Review of Economic Studies, 49, 3-13.

Shaked, A. and J. Sutton, (1987) 'Product Differentiation and Industrial Structure'. The Journal of Industrial Economics, XXXVI (2), 131-146.

Tirole, J., (1988) The Theory of Industrial Organization, The MIT-Press, Cambridge, Mass.

Valetti, T. M., (2000) 'Minimum Quality Standard Under Cournot Competition, Journal of Regulatory Economics, 18, 235-245. 